\title{
Estimativa da pegada hídrica de um grupo de alunos de uma instituição de ensino superior
}

\author{
George Scarpat Giacomin ${ }^{\text {; }}$ Alfredo Akira Ohnuma Jr. ${ }^{2}$ \\ george.sg@fsjb.edu.br
}

1. Faculdades Integradas de Aracruz, Rua Professor Berilo Basilio dos Santos, 180, Aracruz, Brasil.

2. Universidade do Estado do Rio de Janeiro, Rua São Francisco Xavier, 524, Rio de Janeiro, Brasil.

Histórico do Artigo:

Recebido: 18 de outubro de 2016

Aceito: 3 de maio de 2017

Publicado: 18 de julho de 2017

\begin{abstract}
Resumo: A água é um recurso natural fundamental ao planeta e para a qualidade de vida da humanidade. 0 uso indiscriminado dos recursos hídricos acentua a necessidade de trabalhos de modo a garantir sua preservação e gestão de forma mais eficiente. A pegada hídrica surge como um indicador ambiental que se concentra em avaliar as necessidades diretas e indiretas de água para sustentar o estilo de vida de uma pessoa, região, nação, empresa e produto. (HOEKSTRA, 2004). Este trabalho tem como objetivo avaliar a pegada hídrica de um grupo de indivíduos a partir de serviços e produtos consumíveis. A metodologia consiste de aplicar ferramenta de cálculo matemático proposta por Hoekstra, Chapagain e Mekonnen (2005) disponível no site da Water Footprint Network, a partir de questionários individuais para um grupo de 275 alunos de ensino superior das Faculdades Integradas de Aracruz. 0 valor de pegada hídrica de $1632 \mathrm{~m}^{3} /$ ano por aluno resulta acima do valor da pegada hídrica média global de 1385 $\mathrm{m}^{3}$ /ano per capita e abaixo da média nacional, estimada em $2027 \mathrm{~m}$ 3/ano per capita (HOEKSTRA e MEKONNEN, 2011). Conclui-se que embora resulte em um valor favorável em comparação com a média nacional, há necessidade de melhorias em ações de mitigação de consumo, assim como no uso responsável e sustentável dos recursos hídricos, de modo a reduzir o consumo e a poluição da água, e consequentemente, a redução da pegada hídrica. Palavras-chave: Consumo de água, Escassez de água, Sustentabilidade, Educação Ambiental.
\end{abstract}

\section{Estimation of the water footprint of a group of students in a higher education institution}

\begin{abstract}
Water is a fundamental natural resource for the planet and for the quality of life of humankind. The indiscriminate use of water resources accentuates the need for work to ensure its preservation and management more efficiently. The water footprint emerges as an environmental indicator that focuses on assessing the direct and indirect needs of water to sustain the lifestyle of a person, region, nation, company and product. (HOEKSTRA, 2004). This work aims to evaluate the water footprint of a group of individuals from services and consumables. The methodology consists of applying a mathematical calculation tool proposed by Hoekstra, Chapagain and Mekonnen (2005) available on the Water Footprint Network website, from individual questionnaires to a group of 275 higher education students from Faculdades Integradas de Aracruz. The water footprint of $1632 \mathrm{~m} 3$ year per student is above the average global water footprint of $1385 \mathrm{~m}^{3} /$ year per capita and below the national average, estimated at $2027 \mathrm{~m}^{3} /$ year per capita (HOEKSTRA and MEKONNEN, 2011). It is concluded that although it results in a favorable value compared to the national average, there is a need for improvements in actions to mitigate consumption, as well as responsible and sustainable use of water resources, in order to reduce consumption and water pollution, And consequently, the reduction of the water footprint.
\end{abstract}

Keywords: Water consumption, Water shortage, Sustainability, Environmental education. 


\title{
Estimación de la pegada hídrica de un grupo de alumnos de una institución de enseñanza superior
}

\begin{abstract}
Resumen: El agua es un recurso natural clave en el planeta y la calidad de vida de la humanidad. El uso indiscriminado de los recursos hídricos hace hincapié en la necesidad de trabajar para asegurar su conservación y gestión más eficiente. Surge la huella de agua como un indicador ambiental que se centra en la evaluación del agua directo e indirecto debe ser compatible con el estilo de vida de una persona, región, nación, empresa y producto. (Hoekstra, 2004). Este trabajo tiene como objetivo evaluar la huella hídrica de un grupo de individuos de servicios y productos de consumo. La metodología consiste en aplicar herramienta matemática de cálculo propuesto por Hoekstra y Mekonnen Chapagain (2005) disponible en el sitio web Water Footprint Network, a partir de cuestionarios individuales a un grupo de 275 estudiantes de educación superior de Aracruz Universidades Integradas. La cantidad de la huella de agua de $1632 \mathrm{~m}$ 3/año por estudiante resulta mayor que la huella hídrica promedio global de $1385 \mathrm{~m}^{3}$ /año per cápita inferior a la media nacional, estimada en $2.027 \mathrm{~m}^{3} /$ año per cápita (HOEKSTRA y MEKONNEN, 2011). Se concluye que, si bien resulta en un valor favorable en comparación con el promedio nacional, existe la necesidad de mejora en las acciones de mitigación de los consumidores, así como el uso responsable y sostenible de los recursos hídricos con el fin de reducir el consumo y la contaminación del agua y en consecuencia la reducción de la huella de agua.

Palabras clave: Consumo de agua, Escasez de agua, Sostenibilidad, Educación ambiental.
\end{abstract}

\section{INTRODUÇÃO}

Provavelmente, por ocupar dois terços da superfície da Terra, a água foi considerada ao longo dos séculos um recurso infinito, o que se mostra inverídico nos dias atuais. Isso se deve a forma como a humanidade trata a água, causando impactos como sua degradação e escassez. Os resultados destes impactos são muito severos para a população humana, afetando todos os aspectos da vida diária das pessoas, a economia regional e nacional e a saúde humana. Estas consequências podem ser resumidas em: a) degradação da qualidade da água superficial e subterrânea; b) aumento das doenças de veiculação hídrica, como cólera, diarreias agudas, febre tifoide e hepatite A, e impacto na saúde humana; c) diminuição da água disponível per capita; d) aumento no custo da produção de alimentos; e) impedimento ao desenvolvimento industrial e agrícola e comprometimento dos usos múltiplos e f) aumento dos custos de tratamento de água (TUNDISI, 2003).

Mensurar a ausência de equilíbrio ambiental entre a humanidade e os recursos naturais estabelece a inclusão de indicadores de sustentabilidade como ferramenta importante na avaliação do uso correto desses recursos (ERCIN; ALDAYA; HOEKSTRA et al., 2011). A partir de uma perspectiva sobre os recursos hídricos, todos os aspectos da produção e do comércio nos quais a água esteja envolvida passam a requerer uma nova contextualização. Com isso surge em 2002 o conceito de "Pegada Hídrica" introduzido pelo engenheiro holandês Arjen Hoekstra. Trata-se de um indicador de consumo de água que contabiliza a quantidade de água utilizada na 
produção de bens e serviços consumidos pelos habitantes de um país ou região, e considera os fluxos com outros países a partir de produtos importados e exportados.

As estimativas de pegada hídrica consistem de mensurar a quantidade de água envolvida em toda a cadeia de produção, com as particularidades especificas de cada região produtora e as características ambientais e tecnológicas.

Este trabalho tem como objetivo avaliar a pegada hídrica de um grupo de alunos com base em questionários de modelos específicos em uma determinada instituição de ensino. 0 questionário da pegada hídrica é baseado na $O N G$ Water Footprint Network proposto por Hoekstra, Chapagain e Mekonnen.

\section{A IMPORTÂNCIA DA PEGADA HÍDRICA}

Entender a importância da pegada hídrica é fundamental para compreender que a maior parte da água que uma pessoa consome em seus hábitos diários não vem das torneiras de casa, mas sim dos produtos que ela utiliza e consome. Aí estão incluídos desde a precipitação das chuvas nas regiões de produção agrícola até os litros de água consumidos para a produção industrial.

Uma forma de exemplificar esta ideia é quando uma camisa de algodão é vendida de um país para outro, entende-se que a água utilizada em sua fabricação também foi exportada (HOEKSTRA et al 2007). 0 mesmo ocorre com carregamentos de soja, minério de ferro e tantas outras mercadorias. Para países com escassez de água, pode ser interessante a importação de água virtual - por meio da importação de mercadorias que consomem muita água em sua produção. Desta forma, eles podem aliviar as pressões sobre suas próprias fontes de água.

0 resultado da escassez hídrica em algumas partes do planeta é um comércio mundial de água, na forma de bens e produtos. Os países e regiões que dispõem de água produzem bens para atender aqueles onde ela é escassa. Esse sistema passa a representar um problema quando as regiões produtoras, por falta de mecanismos adequados de gestão de seus recursos hídricos, passam a explorá-los em um ritmo superior à capacidade de regeneração do ambiente local (CHAPAGAIN e HOEKSTRA, 2004a). 
0 estado do Espírito Santo enfrenta a crise hídrica mais importante de sua história ${ }^{1}$ Com início em 2014, a redução das chuvas ocasionou uma redução recorde da vazão dos rios, o que prejudicou drasticamente o abastecimento de água no estado. A situação mais grave é verificada no norte do Espírito Santo, onde já se registram períodos com baixa pluviosidade desde a década de 50. No entanto, a gravidade da seca atual trouxe efeitos inéditos até mesmo para a região de Aracruz onde foi implantado o rodizio no abastecimento de água para a população.

Informações assim revelam uma situação caótica e que acarretaram discussões sobre a escassez de água no meio urbano brasileiro, principalmente no que tange a implementação de medidas necessárias para reversão deste quadro. Neste sentido que a pegada hídrica se torna um instrumento extremamente relevante para a conscientização do uso racional da água.

Globalmente, a água é poupada se produtos agrícolas são comercializados de regiões com alta produtividade e que requerem menos água para produção, para aquelas com baixa produtividade e que necessitam de muita água em sua produção. Neste sentido, se países importadores produzissem internamente todos os produtos agrícolas importados, isto exigiria 1600x $10^{9} \mathrm{~m}^{3}$ de água por ano, no entanto, os produtos são produzidos com apenas 1200x109 $\mathrm{m}^{3}$ /ano nos países exportadores, havendo economia de recursos hídricos globais em aproximadamente 400 bilhões $\mathrm{m}^{3}$ /ano (WWF, 2010).

A pegada hídrica global relacionada à produção agrícola e industrial e abastecimento doméstico de água para o período 1996-2005 foi de $9087 \mathrm{Gm}^{3}$ /ano (MEKONNEN e HOEKSTRA, 2011). A agricultura é o setor com maior gasto de água, estima-se que para o período entre 1996 e 2005, ela responda por 92\% do consumo de água total no planeta, superando de longe o volume gasto no setor industrial com 4,4\% e o consumo doméstico com 3,6\%. 0 tamanho da pegada hídrica global é influenciado principalmente pelo consumo de alimentos e outros produtos agrícolas (HOEKSTRA e MEKONNEN, 2012).

\section{A PEGADA HÍDRICA DE UM PAÍS}

Em termos totais, a China é o país com a maior pegada hídrica total no mundo, com um valor total de $1368 \mathrm{Gm}^{3}$ /ano, seguido pela Índia e os EUA com 1145 Gm³/ano e 821 Gm³/ano,

'Disponível em https://www.cesan.com.br/noticia/como-o-espirito-santo-atravessa-a-pior-crise-hidrica-da-suahistoria/ 
respectivamente. 0 Brasil é o $4^{0}$ nesse ranking de consumo de água, com um valor de pegada hídrica total de $355 \mathrm{Gm}^{3}$ /ano (MEKONNEN e HOEKSTRA, 2011). Quando somadas, essas quantias de consumo equivalem a 38\% de todo o uso de água na produção de bens do planeta. Obviamente, os países com grandes populações têm uma pegada hídrica elevadas. Por isso, é mais interessante observar a pegada hídrica per capita (MEKONNEN e HOEKSTRA, 2011).

A dimensão da pegada hídrica de um país é diretamente afetada pelo consumo de alimentos e outros produtos agrícolas. Os quatro principais fatores de determinação da pegada hídrica de um país são: o volume de consumo (em relação ao Produto Interno Bruto - PIB), o padrão de consumo (por exemplo, alto e baixo consumo de carne), as condições climáticas (condições de crescimento das culturas agrícolas) e práticas agrícolas (uso eficiente da água) (MEKONNEN e HOEKSTRA, 2011). A influência desses indicadores faz com que a pegada hídrica varie de país para país.

Então se tornando relevante analisar, por exemplo, as implicações da produção de carne bovina sobre o uso dos recursos hídricos, não só porque a produção mundial de carne quase dobrou no período de 1980 a 2004 (FA0, 2005), mas também porque a produção de carne está projetada para dobrar no período entre 2000 e 2050 (STEINFELD et al., 2006).

A tabela 1 mostra como o volume de consumo de carne, pelo seu valor de pegada hídrica, pode influenciar no valor total da pegada hídrica do país. Por exemplo, nos EUA, a pegada hídrica média de um quilo de carne bovina consumida é $14500 \mathrm{~L} / \mathrm{kg}$, enquanto no Reino Unido este é 9900 L/kg. Já na Bolívia, o consumo de carne é de 1,3 vezes a média global, mas a pegada hídrica por tonelada de carne é de cinco vezes a média global. 
Tabela 1 - Relação entre consumo de carne, pegada hídrica da carne por país e pegada hídrica por país.

\begin{tabular}{cccc}
\hline País & $\begin{array}{c}\text { Consumo de Carne } \\
\text { (Kg/pessoa/ano) }\end{array}$ & $\begin{array}{c}\text { Pegada Hídrica da } \\
\text { Carne }(\mathrm{L} / \mathbf{k g})\end{array}$ & $\begin{array}{c}\text { Pegada Hídrica por habitante } \\
\left(\mathbf{m}^{\mathbf{3}} / \mathbf{a n o} \text { per capita) }\right.\end{array}$ \\
\hline Bolívia & 12 & 77000 & 3468 \\
EUA & 43 & 14500 & 2842 \\
Brasil & 32 & 19400 & 2027 \\
México & 23 & 17500 & 1978 \\
Ucrânia & 10 & 12600 & 1575 \\
Reino Unido & 18 & 9900 & 1258 \\
China & 5 & 13700 & 1071 \\
\hline Média Mundial & 9 & 15400 & 1385
\end{tabular}

Fonte: Adaptada de MEKONNEN e HOEKSTRA, 2011, e ROPPA, 2006.

Isso mostra que quanto maior for a consumo de carne onde a pegada hídrica do produto carne bovina for alta, maior será a pegada hídrica do país e do indivíduo.

\section{PEGADA HÍDRICA DE UM INDIVÍDUO OU GRUPO DE INDIVÍDUOS}

A pegada hídrica de um indivíduo é definida como o volume total de água doce consumida e poluída utilizada para a produção de produtos e serviços usados pelo indivíduo. A pegada hídrica de um grupo de indivíduos é igual à soma das pegadas hídricas dos indivíduos (HOEKSTRA, CHAPAGAIN, ALDAYA e MEKONNEN, 2011).

A pegada hídrica de um indivíduo é calculada pela soma da pegada hídrica direta e a pegada hídrica indireta do indivíduo. A pegada hídrica direta refere-se ao consumo direto de água e a poluição que está relacionada ao uso da água em casa para seu consumo básico. A pegada hídrica indireta refere-se ao consumo indireto de água e da poluição dela que pode estar associada com a produção dos bens e serviços utilizados pelo consumidor. Como a água que foi utilizada e a poluição gerada para produzir os produtos alimentares, a roupa, a energia elétrica, o papel (HOEKSTRA, CHAPAGAIN, ALDAYA e MEKONNEN, 2011). 
Para se determinar a pegada hídrica de um indivíduo se faz necessário o uso de uma ferramenta de cálculo, uma calculadora eletrônica encontrada no site ${ }^{2}$ da organização Water Footprint Network. Esta calculadora constitui de um breve conjunto de perguntas que fará o indivíduo analisar sobre quantidade de água consumida, seu uso doméstico e como a água se conecta a praticamente todos os aspectos de sua vida. A calculadora ajuda a explorar a forma como a água é usada, incluindo o consumo direto e indireto. Os cálculos baseiam-se nas necessidades de água por unidade de produto referente ao seu país de residência. Através dela foi elaborado um questionário com perguntas referentes ao consumo de água de um indivíduo. A calculadora busca informações de consumo direto e indireto de água nas atividades cotidianas das pessoas e, por sua vez, o consumo indireto é baseado na quantidade de água virtual (fluxo das águas azul, verde e cinza) utilizada na produção de bens e serviços. Ela é dividida por tipo de consumo como: alimentos, consumo doméstico e industrial.

A pegada hídrica média global por indivíduo relacionada com o consumo é de 1385 m³/ano per capita no período 1996-2005. Um habitante dos Estados Unidos tem pegada hídrica média de $2842 \mathrm{~m}^{3}$ /ano per capita, enquanto os cidadãos na China e Índia têm pegada hídrica de 1071 e $1089 \mathrm{~m}^{3}$ /ano per capita, respectivamente (HOEKSTRA e MEKONNEN, 2012). Os países industrializados têm pegada hídrica na faixa de 1250 - $2850 \mathrm{~m}^{3}$ /ano per capita, enquanto os países em desenvolvimento mostram uma variação maior de 550-3800 mªno per capita, como observado na figura 1.

\footnotetext{
${ }^{2}$ Site para acesso à calculadora da Water Footprint Network: http://www.waterfootprint.org/?page=cal/WaterFootprintCalculator
} 


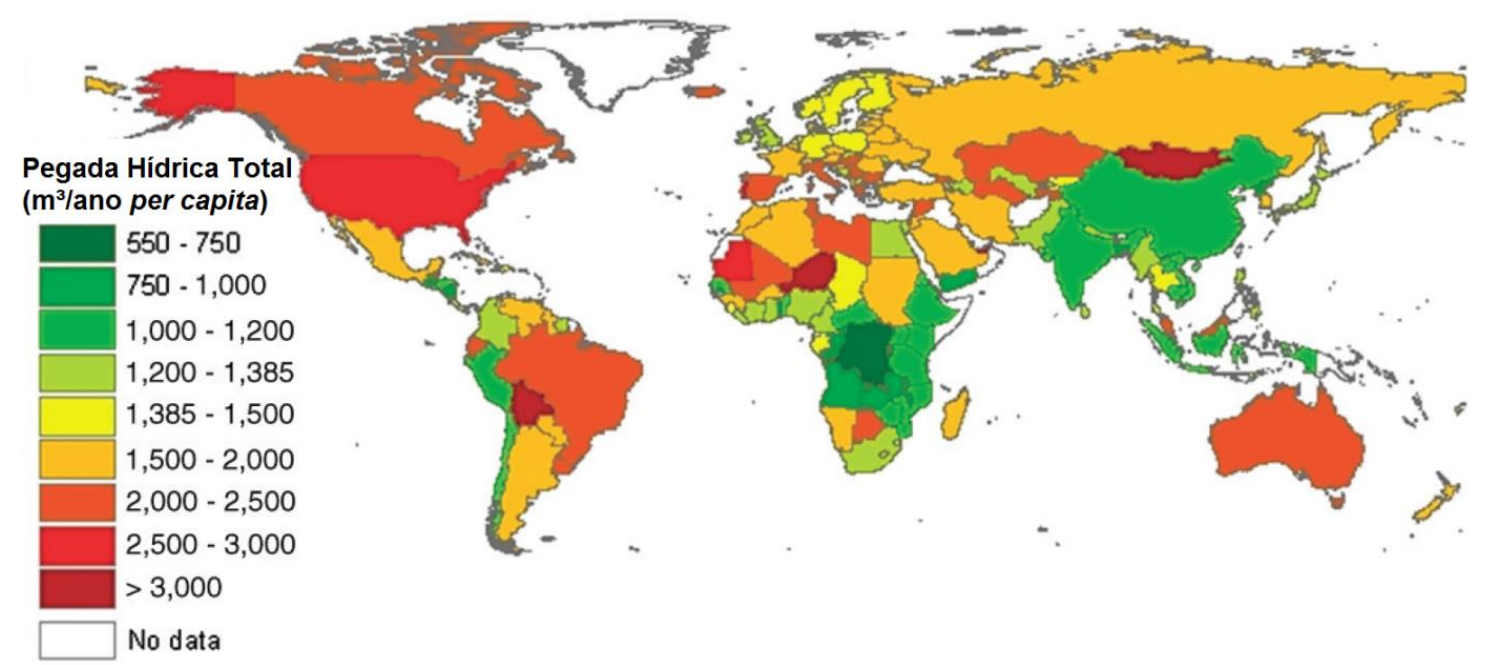

Figura 1. Pegada hídrica média nacional per capita (m3/ano per capita) no período entre 1996 e 2005. Países em verde têm a pegada hídrica média menor que a média global. Países em amarelo e vermelho têm pegada hídrica média acima da média global Fonte: HOEKSTRA e MEKONNEN, 2012.

\section{MATERIAIS E MÉTODOS}

Este trabalho consiste no cálculo a pegada hídrica de um grupo de indivíduos, sendo considerada uma pesquisa quantitativa descritiva. Para obter 0 valor da pegada hídrica foi necessário adaptar a metodologia de cálculo sugerida no Manual de Avaliação da Pegada Hídrica, desenvolvido pela Water Footprint Network, publicado em 2009 e revisto em 2011, que contém o padrão global de avaliação da pegada hídrica (HOEKSTRA, CHAPAGAIN, ALDAYA e MEKONNEN, 2011).

Para esta pesquisa, utilizou-se o procedimento de levantamento de dados por meio de questionários aplicados a um grupo de alunos dos cursos de Engenharia Química, Engenharia Mecânica, Pedagogia e Administração da FAACZ - Faculdades Integradas de Aracruz nos meses de Março e Abril de 2012. A escolha dos cursos foi aleatória e foram entrevistados 275 alunos de um total de 1650 alunos da instituição, que corresponde a 16,67\% do total de alunos, representativamente com um grau de confiança de 93,06\% e uma margem de erro de $\pm 5 \%$ em relação à população estudada. Esta abordagem também se mostrou eficaz devido à pronta resposta quanto às dúvidas referentes ao questionário por parte do entrevistador.

Para facilitar o cálculo da pegada hídrica, os dados obtidos na pesquisa foram inseridos na calculadora, que foi a transposição do site da Water Footprint Network (disponível em http://waterfootprint.org/en/) para a planilha do Microsoft Excel. Os coeficientes de 
multiplicação de cada item ou produto analisado possuem valores de cálculo baseados nas necessidades de água por unidade de produto referente a seu país de origem, no caso da pesquisa o Brasil. Depois de aplicado o questionário, os dados foram tabulados e analisados, e então foi possível obter a média per capita de pegada hídrica dos indivíduos, dentre outros indicadores.

Devido ao fato de haver poucos estudos relacionados ao cálculo de pegada hídrica do indivíduo no Brasil, não foi possível obter muitos parâmetros de comparação.

\section{RESULTADOS E DISCUSSÃ0}

A pegada hídrica do indivíduo é formada por três componentes: alimentos, doméstico e industrial, conforme demonstração dos resultados obtidos na pesquisa na tabela 2, que mostra as médias de cada componente.

Tabela 2 - Resultados obtidos na pesquisa para pegada hídrica do indivíduo (m3/ano per capita)

\begin{tabular}{lcc}
\hline \multicolumn{1}{c}{ Componentes } & $\begin{array}{c}\text { Pegada Hídrica do Indivíduo } \\
\left(\mathrm{m}^{3} / \mathrm{ano}\right)\end{array}$ & Percentual \\
\hline Alimentos & 1231 & $76 \%$ \\
Doméstico & 214 & $13 \%$ \\
Industrial & 187 & $11 \%$ \\
\hline Pegada hídrica do indivíduo & 1632 & $\mathbf{1 0 0 \%}$ \\
\hline Fonte: Autoria própria. & &
\end{tabular}

A figura 2 representa a pegada hídrica de cada indivíduo composta pelas categorias de alimento, doméstico e industrial, bem como a média de pegada hídrica encontrada na pesquisa. 


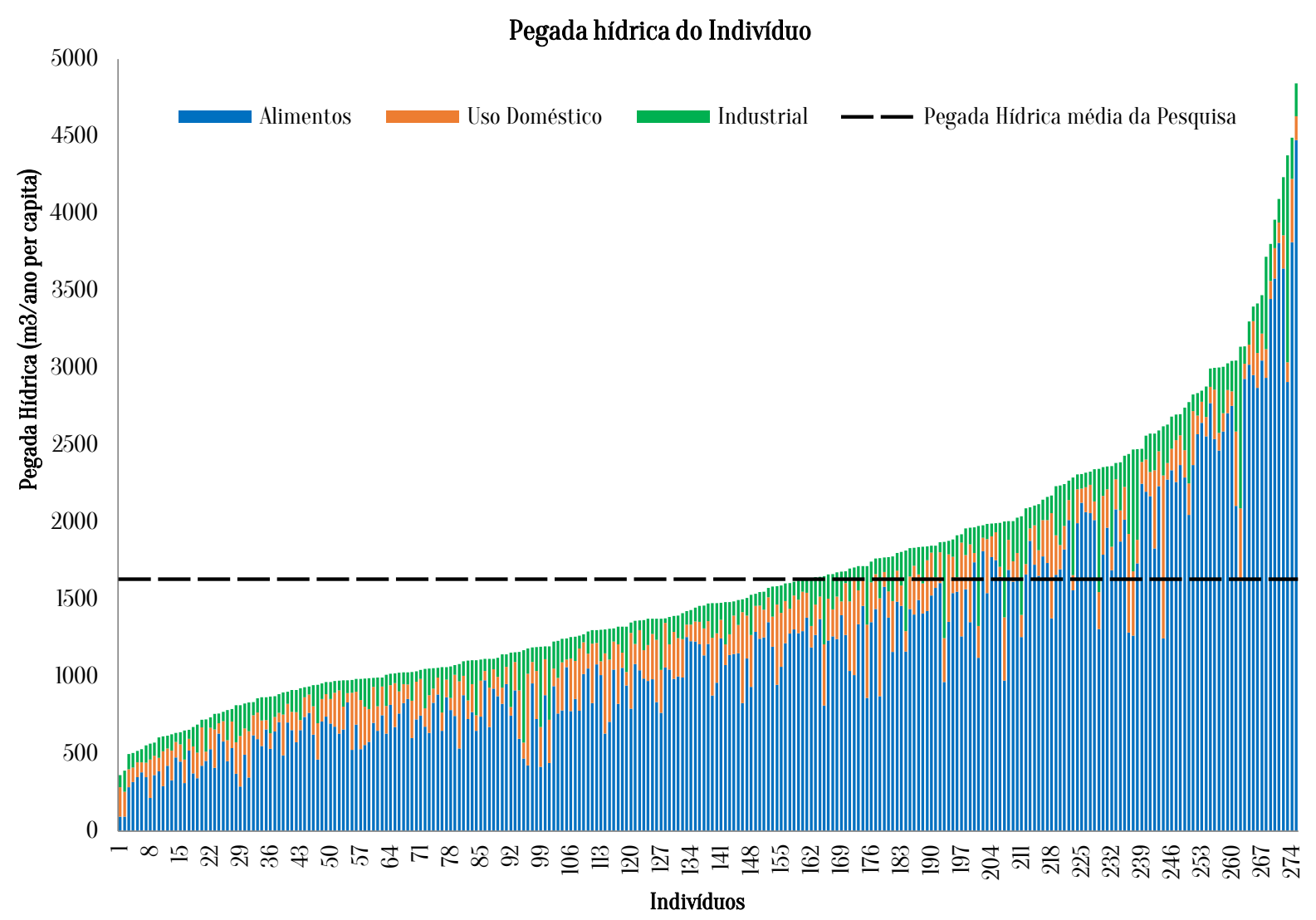

Figura 2. Representação da pegada hídrica do indivíduo com suas categorias.

Fonte: Própria.

Os resultados da pesquisa para a média da pegada hídrica do indivíduo foram de 1632 $\mathrm{m}^{3}$ /ano e este valor ficou abaixo da média brasileira e acima da média mundial. Isso pode ser observado na figura 3, que compara os resultados obtidos de pegada hídrica do Indivíduo com a média do Brasil e a média mundial.

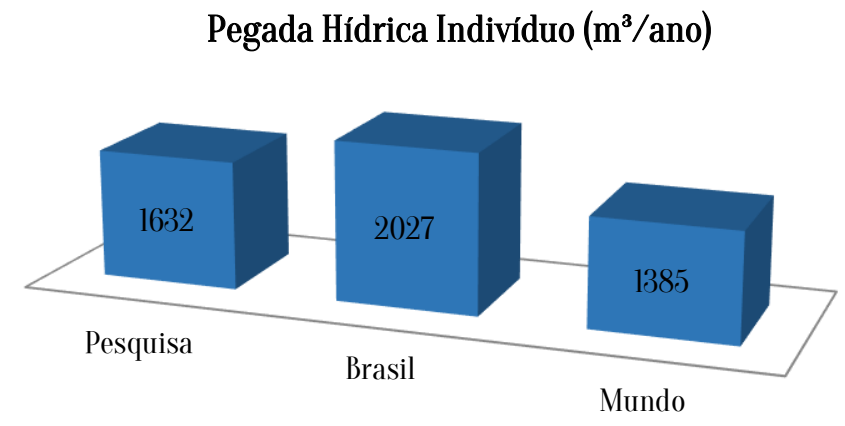

Figura 3. Valor médio de pegada hídrica do indivíduo encontrado na pesquisa comparado com a pegada hídrica média do indivíduo no Brasil e no Mundo.

Fonte: Própria. 
A figura 4 mostra outra comparação entre valores de pegada hídrica do indivíduo na pesquisa e entre alguns países, mas dividida em categorias de consumo de água como: alimentos, uso doméstico e industrial. 0s resultados da pesquisa mostram que a pegada hídrica relacionada ao consumo de alimentos é menor que a média do Brasil e a média mundial. Já para os resultados da pesquisa referentes à pegada hídrica relacionada ao consumo doméstico e industrial, mostram que estes superam a média do Brasil e a média mundial.

\section{Comparação entre a pegada hídrica do indivíduo ( $\mathrm{m}^{3}$ /ano per capita)}

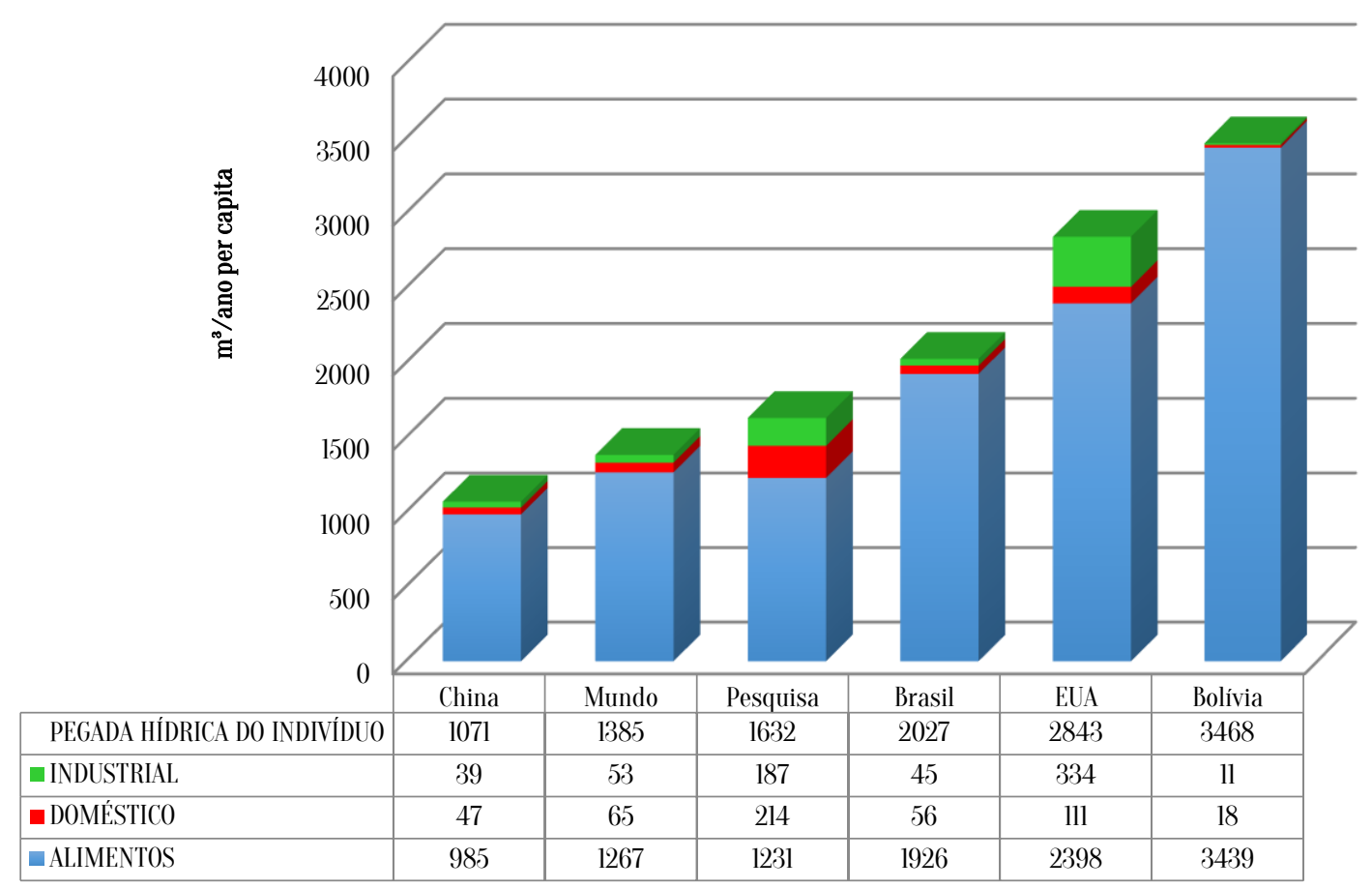

Figura 4. Comparação entre os resultados obtidos de pegada hídrica do indivíduo e suas componentes, com a média brasileira e mundial.

Fonte: Própria.

Na figura 4 também pode ser verificado que nos resultados obtidos na pesquisa, $76 \%$ (1231 m³/ano per capita) da pegada hídrica média do indivíduo pesquisado é referente ao consumo de alimentos, abaixo da média do Brasil de 95\% (1926 m³/ano per capita) e da média mundial de 92\% (1267 m³/ano per capita). 0 mesmo não pode ser observado com o consumo doméstico que representa $13 \%$ (214 $\mathrm{m}^{3}$ /ano per capita) da pegada hídrica média do indivíduo 
pesquisado, pois os valores ficaram acima da média do Brasil que é de $3 \%$ ( $56 \mathrm{~m}^{3} /$ ano per capita) e da média mundial de $5 \%$ (65 $\mathrm{m}^{3} /$ ano per capita). Isso ocorre similarmente com o consumo industrial de $11 \%$ (187 $\mathrm{m}^{3}$ /ano per capita) da pegada hídrica média do indivíduo pesquisado que ficou acima da média do Brasil de $2 \%$ (45 m³/ano per capita) e da média mundial com 4\% (53 $\mathrm{m}^{3}$ /ano per capita). A mesma figura 4 representa uma relação da pegada hídrica do indivíduo encontrada na pesquisa com a média de um país desenvolvido (EUA), um país subdesenvolvido (Bolívia), a China, o Brasil e média mundial. Observa-se que em países desenvolvidos, como 0 consumo de bens e serviços e de alimentos é maior, isso se traduz imediatamente em pegadas hídricas mais altas. Mas não é só o volume de consumo que determina a demanda de água por pessoa e sim a composição do padrão de consumo, porque alguns produtos em particular, exigem uma grande quantidade de água como a carne bovina e o arroz, por exemplo. Em muitos países subdesenvolvidos há uma combinação de condições climáticas desfavoráveis (alta demanda evaporativa) e má prática agrícola (resultando em baixa produtividade da agricultura), que contribui para uma pegada hídrica elevada.

A pesquisa apontou ainda a contribuição de cada categoria de alimentos para a pegada hídrica do indivíduo (figura 5). Estas categorias são divididas em:

- Cereais (arroz, trigo, milho, feijão, etc.)

- Carnes (bovina, de frango, suína, etc.)

- Vegetais (hortaliças, cebola, repolho, cenoura, etc.)

- Frutas (banana, maçã, laranja, etc.)

- Lácteos (leite e derivados)

- Estimulantes (café, chá, etc.)

- Gorduras (de animais)

- Açúcar

- 0vos

- Outros (inclui óleo vegetal, raízes ricas em amido (mandioca, batata, etc.), açúcar e adoçantes, leguminosas, nozes, etc.). 


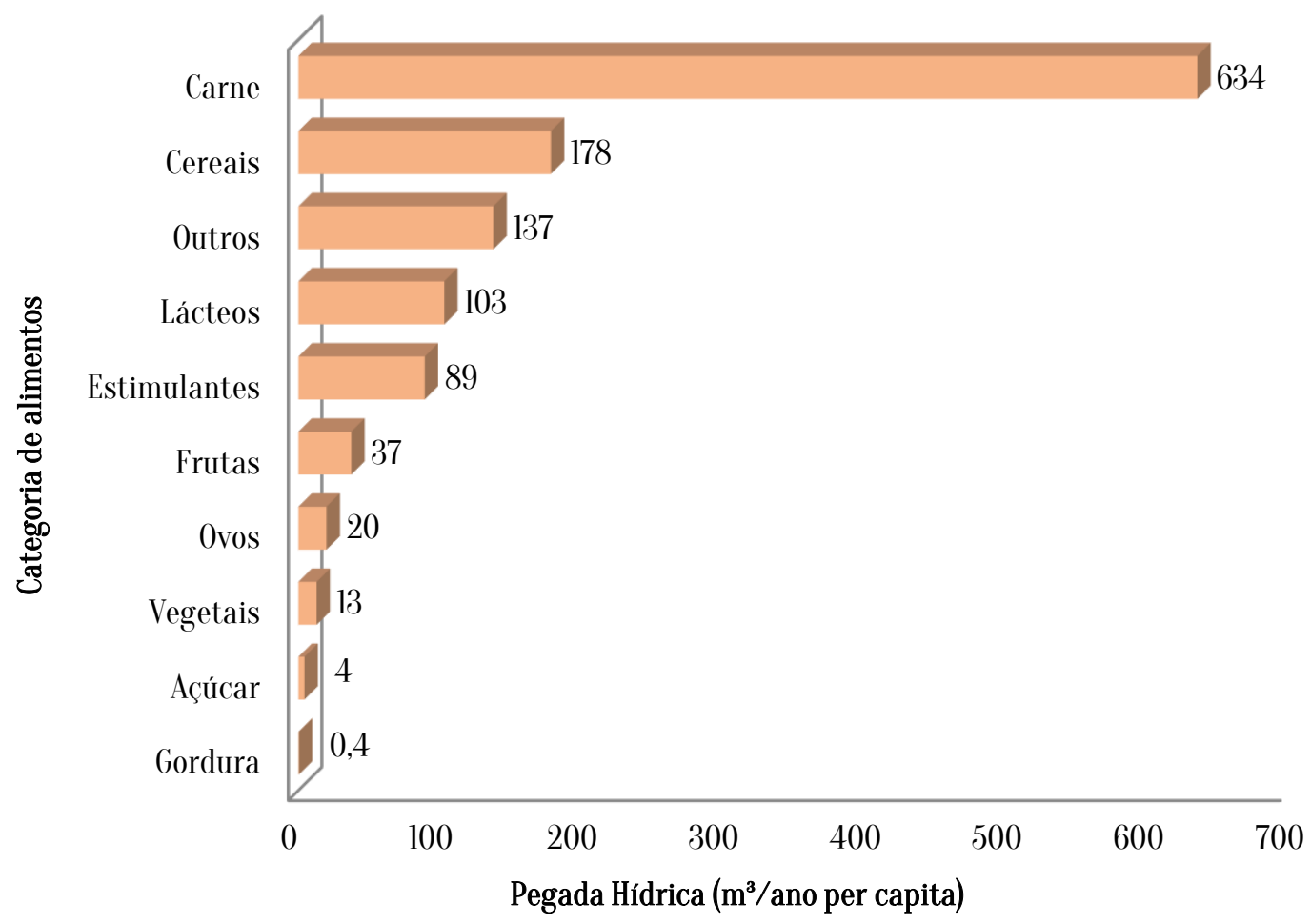

Figura 5. Contribuição de cada categoria de alimentos para a pegada hídrica do indivíduo. Fonte: Própria.

A figura 5 mostra que dentre os segmentos de consumo relacionados na calculadora, os alimentos apresentam os resultados mais significativos para 0 consumo de água dos entrevistados. Tal fato pode ser explicado pela grande quantidade de água utilizada na irrigação das plantações e pastagens para alimentação de animais, além do gato hídrico no beneficiamento da carne. Desta forma, referente ao consumo indireto de água, o que mais impacta é o consumo de carne, pois seu consumo específico de água é elevado comparado com outras categorias de alimentos, seguido pelos cereais.

\section{CONCLUSÃ0}

A presente pesquisa apresenta valores referentes à pegada hídrica do indivíduo abaixo da média brasileira e acima da média mundial - $1632 \mathrm{~m}$ 3/ano per capita obtidos na pesquisa, 2027 m³/ano per capita da população brasileira e 1385 m³/ano per capita da população mundial. Isso se explica, em parte, pelo menor valor de pegada hídrica encontrada para o consumo de alimentos, pois a água necessária para produzir alimentos e produtos de origem animal é o 
principal fator que acarreta o aumento da pegada hídrica. Desta forma, a pegada hídrica de um indivíduo está diretamente ligada ao seu padrão de consumo e a oferta de produtos disponíveis, sendo que cerca de 13\% da sua pegada hídrica está no uso doméstico, com consumo de água na cozinha e no banheiro, e 87\% estão relacionados com aos produtos adquiridos, especialmente os agrícolas. 0s indivíduos da pesquisa também apresentam consumo individual de água acima da média brasileira, devido aos hábitos de higiene, cultura e estilo de vida, renda, forma de acesso à água, medição de consumo e pressão na rede de abastecimento.

Para que haja redução da pegada hídrica, devem-se adotar técnicas de produção que exijam uma menor quantidade de água por unidade de produto. Do mesmo modo, na agricultura devem ser aplicadas novas técnicas para captação e uso da água da chuva e de irrigação suplementar. Mudar os padrões de consumo, ao adquirir produtos de menor valor agregado de água virtual também são estratégias para reduzir a pegada hídrica. Para que haja uma redução no consumo individual de água, se faz necessário a mudança de atitude por parte das pessoas. Como indivíduo, pode-se reduzir a pegada hídrica direta na instalação de sanitários ecológicos que consomem menos água por descarga, ou simplesmente na redução do consumo para higiene pessoal ou na irrigação de jardins.

Este estudo proporciona um importante apoio para uma estimativa mais intensa de como os produtos e seus consumidores contribuem para o problema global de apropriação de água doce, referente a escassez de recursos hídricos que atendam aos padrões de consumo humano. 0 trabalho estabelece também como a relação entre produtos com excessivo uso de água e consumo pode ajudar no diálogo entre consumidores, produtores e governo sobre como partilhar a responsabilidade no uso racional da água.

\section{REFERÊNCIAS BIBLIOGRÁFICAS}

AgENCIA NACIONAL DE ÁGUAS - ANA, A Água no Brasil e no Mundo, 2006, Disponível em: http://www.ana.gov.br/GestaoRecHidricos/InfoHidrologicas/mapasSIH/l- AAguaNoBrasilENoMundo.pdf. Acesso em $03 / 11 / 2011$

AGENCIA NACIONAL DE ENERGIA ELÉTRICA - ANEEL e ANA, Introdução ao gerenciamento de recursos hídricos. Brasília, 2001.

CHAPAGAIN, A.K. e HOEKSTRA, A.Y. Water footprints of nations, UNESCO-IHE, 2004.

CHAPAGAIN, A.K. e HOEKSTRA, AY (2004a). Water footprints of nations. Value of Water Research Report Series. UNESCO-IHE, v.l, n. 16, Nov, 80p, 2004. 
CHAPAGAIN, A.K. e HOEKSTRA, AY (2004b) Water footprints of nations. Value of Water Research Report Series. UNESCO-IHE, v.2, n. 16, Nov, 240p, 2004.

CHAPAGAIN, A.K. e HOEKSTRA, A.Y. The blue, green and grey water footprint of rice from production and consumption perspectives, Ecological Economics, 70(4): 749-758, 2011.

CHAPAGAIN, A.; HOEKSTRA, A.; SAVENIJE, H.. Saving water through global trade. Value of Water. Research Report Series n.17. Setembro 2005. UNESC0-IHE, Delft, Holanda, 2005.

ERCIN, A. E.; ALDAYA, M. M.; HOEKSTRA, A. Y. Corporate water footprint accounting and impact assessment: the case of the water footprint of sugar-containing carbonated beverage, Water Resources Management, v. 25, p. 721-741, 2011.

HOEKSTRA, A.Y. e HUNG, P.Q. Globalisation of water resources: international virtual water flows in relation to crop trade, Global Environmental Change, 15(1): 45-56, 2005.

HOEKSTRA, A.Y. Human appropriation of natural capital: Comparing ecological footprint and water footprint analysis, Value of Water Research Report Series $n^{\circ} .23$, UNESC0-IHE, 2007.

HOEKSTRA, A.Y. e CHAPAGAIN, A.K. Water footprints of nations: water use by people as a function of their consumption pattern, Water Resources Management. 21(1): 35-48, 2007.

HOEKSTRA, A. Y., E A. K. CHAPAGAIN. Globalization of Water: Sharing the Planet's Freshwater Resources. Blackwell Publishing, Oxford, UK, 2008.

HOEKSTRA, A.Y., CHAPAGAIN, A.K., ALDAYA, M.M. e MEKONNEN, M.M. Water footprint manual: State of the art 2009, Water Footprint Network, Enschede, the Netherlands, 2009.

HOEKSTRA, A.Y., CHAPAGAIN, A.K., ALDAYA, M.M. e MEKONNEN, M.M. The water footprint assessment manual: Setting the global standard, Earthscan, London, UK. 2011.

HOEKSTRA, A.Y. E MEKONNEN, M.M. The water footprint of humanity, Proceedings of the National Academy of Sciences, doi/10.1073/pnas.1109936109., 2012.

HOEKSTRA, A.Y. The hidden water resource use behind meat and dairy, Animal Frontiers, 2(2): 3-8, 2012.

OMM/UNESC0, Hay suficiente água em el mundo?, 1997.

R0PPA, L., Perspectivas da produção mundial de carnes, 2006 a 2030. Revista Pork World, n.34, p.16-27, 2006.

STEINFELD, H., P. GERBER, T. WASSENAAR, V. CASTEL, M. ROSALES, AND C. DE HAAN. Livestock's long shadow: Environmental issues and options. FA0, Rome, Italy, 2006.

TRIOLA, Mário F. Introdução à Estatística. 7ª Ed. Rio de Janeiro: LTC, 1999.

TUNDISI, J. G. Recursos hídricos no futuro: problemas e soluções. Estud. av. São Paulo, v. 22, n. 63, 2003.

TUNDISI, J. G. Água no século XXI - enfrentando a escassez. São Carlos: Rima, 2003.

UERJ - Universidade do Estado do Rio de Janeiro, Declaração de Dublin, s.d., consulta em www.meioambiente.uerj.br/emrevista/documentos/dublin.htm, Acesso em 27/11/2010.

UNESCO-IHE, Institute for Water Education: Annual Report, 2004

WORLD WATER ASSESSMENT PROGRAMME - WWAP, The United Nations World Water Development Report l: Water for people, water for life, UNESCO Publishing, Paris / Berghahn Books, Nova York, 2003.

WORLD WIDE FUND FOR NATURE - WWF, A Pegada Hídrica do Consumo, Relatório Planeta Vivo 2010. Brasil, agosto 2010 .

WORLD WIDE FUND FOR NATURE - WWF, Relatório Planeta Vivo 2012. Portugal, Maio de 2012. 